\title{
Indigenous Knowledge for Climate Smart Agriculture-A Review
}

\author{
Girma Amare*, Dubiso Gacheno \\ Haramaya University, College of Agriculture and Environmental Science, P.O.Box 138, Dire Dawa, Ethiopia.
}

\begin{abstract}
How to cite this paper: Girma Amare, Dubiso Gacheno. (2021) Indigenous Knowledge for Climate Smart Agriculture-A Review. International Journal of Food Science and Agriculture, 5(2), 332-338.

DOI: 10.26855/ijfsa.2021.06.019
\end{abstract}

Received: April 16, 2021

Accepted: May 18, 2021

Published: June 28, 2021

*Corresponding author: Girma Amare, Haramaya University, College of Agriculture and Environmental Science, P.O.Box 138, Dire Dawa, Ethiopia.

Email: girmare2017@gmail.com

\begin{abstract}
Climate change significantly threatens rural livelihoods in sub-Saharan Africa. This is due to rural community of SSA is relatively more susceptible to the effect of climate change than others regions. The SSA region is exposed to climate risk through increased temperature, changes in rainfall patterns and variations in intensity and frequency of extreme weather events such as drought and floods. Even though, there is a changeover generation local farmers have been adjusting to these changes trough their indigenous knowledge which was impulse from one generation to others usually by word of mouth. The objective of this paper is to review indigenous knowledge for Climate Smart Agriculture. Research on Climate Smart Agriculture has revealed that many agricultural technologies and practices that can affect climate change adaptation in agriculture in rural agro-based communities and literature has shown that indigenous people have been excellent in providing weather smart information services. However, adoption of the same demonstrated Climate Smart Agricultural innovations which incorporate indigenous knowledge is still low in developing countries. Thus, strengthening the role of IK in climate change effects controlling is likely to recover adaptation to climate change in smallholder farming communities. Improved adaptation, capacity building and integrating indigenous knowledge with Climate Smart Agriculture practices might be crucial to enhancing effective community resilience to climate change.
\end{abstract}

\section{Keywords}

Climate Change, Climate Smart Agriculture, Indigenous Knowledge

\section{Introduction}

Agriculture remains to be the leading sector that contributes enormously to economic development in Africa [1, 2]. More importantly, throughout the Sub-Saharan Africa (SSA) region, the sector is hailed as the main engine of economic growth and poverty reduction. Despite its significant contribution to livelihoods, the sector faces a persistent challenge due to depletion of natural resources and soil erosion [3].

Climate change significantly threatens rural livelihoods in sub-Saharan Africa (SSA). This is partly because rural communities in Africa, particularly SSA, are relatively more vulnerable to the effects of climate change than other regions [4]. The SSA region is exposed to climate risk through increased temperature, changes in rainfall patterns and variations in intensity and frequency of extreme weather events such as drought and floods [4].

Even though changes have been occurring over generations, rural farmers have been adapting to these changes throughout their life using local environmental knowledge [5]. The knowledge is relatively cheap, readily available to rural farmers, and it is a climatically smart tool for sustainable development and the management of climate variability [6]. Environmental problems vary spatiotemporarily, but rural farmers, through continued experimentation, trial and error, and sustained interactions with their local environment have developed a vast local knowledge about nature in their locale that they use in coping with and solving their problems, amongst which are climate-related problems [7]. 
UNESCO has a well-established program on preserving traditional knowledge, called Local and Indigenous Knowledge Systems, LINKS. This program was one of the key pillars that contributed to the framing of the Millennium Development Goals (MDGs) of poverty eradication and of environmental sustainability. The same program has been expanded and incorporated in the Post-2015 Development Agenda (Sustainable Development Goals-SDGs) to empower local and indigenous peoples in various aspects of environmental management by advocating and mobilizing their unique knowledge and practices in climate change adaptation [8].

IK is the institutionalized local knowledge built upon and passed on from one generation to another, usually by word of mouth. IK is often treated as secondary in climate change adaptation debates [9, 10], even though it can form the basis for effective adaptation to climate change affects in smallholder farming communities. Notwithstanding a variety of terminology used to refer to local environmental knowledge (LEK), traditional ecological knowledge (TEK), indigenous knowledge (IK), and indigenous traditional knowledge [11]. All the terminology has similar meanings and is used interchangeably to refer to the local environmental or traditional knowledge and skills held by indigenous people, developed outside the formal scientific domain, embedded in culture and steeped in tradition through oral tradition [12].

Climate Smart Agriculture (CSA) has been presented as an alternative form of agriculture for conserving the environment while addressing the food needs of the world's population [13]. The concept was originally put forth in 2010 by FAO after the Hague Conference on Agriculture, Food Security and Climate Change in 2009 [14, 15]. According to FAO [14], the main aim of CSA is to repackage agriculture in the context of a changing climate, to assure a 'triple win', thus, adaptation, mitigation and development.

Most climate change research focuses on rainfall changes because of its direct effect on farming to the neglect of other equally important factors that affect livelihoods. It is evident that scientific knowledge systems need to be complemented with indigenous knowledge systems for enhancing effective community resilience to climate change. Agricultural technologies and practices that can affect climate change adaptation in agriculture in rural agro-based communities [16]. However, adoption of the same proven climate-smart agricultural innovations is still low in developing countries and particularly in the SSA region $[16,17,18]$. Therefore, strengthening the role of IK in climate change effects management is likely to improve adaptation to climate change in smallholder farming communities in SSA. Improved adoption and scaling of climate-smart agriculture innovations are likely to benefit significantly.

\section{Objectives}

- $\quad$ To review indigenous knowledge for Climate smart agriculture in Sub-Saharan Africa.

- To review evolution of indigenous knowledge for Climate smart agriculture in Sub-Saharan Africa.

- To review role of indigenous knowledge for Climate smart agriculture in Sub-Saharan Africa

\section{Literature Review}

\subsection{The emergence of indigenous knowledge in the global climate change arena}

Global climate change was identified in the 1980s as one of humanity's most daunting challenges [19, 20]. This recognition led to the establishment of the Intergovernmental Panel on Climate Change (IPCC) in 1988, and the United Nations Conference on Environment and Development in 1992 (Earth Summit, Rio de Janeiro, Brazil) that established the United Nations Framework global climate change debate has largely concentrated on particular areas of the planet-low-lying tropical islands and coastlines, high-altitude zones, tropical forests and the polar regions [21]. It so happens that most of these areas, except ice-covered Antarctica is home to indigenous peoples. Despite the world's growing interest in indigenous peoples and their homelands as harbingers of the impacts of planetary climate change, much work needs to be done to understand their concerns and appreciate their knowledge.

\subsection{Characteristics of indigenous knowledge}

All the definitions of IK support the idea that IK is developed from experience gained over time and is adapted to local community cultures and their environment. Also, traditional knowledge is transmitted orally from one generation to another, and it tends to be collectively owned. IK is often in the form of stories, proverbs, folklore, cultural values, rituals, beliefs, community laws, local languages and agricultural practices [22]. IK is also important to decision making on aspects of day to day life for the rural people.

\subsection{Role of indigenous knowledge in the adoption and scaling of climate-smart agriculture in Sub-Saharan Africa.}

Literature has shown that indigenous people have been excellent in providing weathersmart information services [5] for agriculture. Literature from SSA confirms the reliance on tree phenology, animal behavior, astronomy and moon movements, just to give a few examples, by indigenous people to predict climate (i.e. onset of rains, and season quality) 
[12, 23, 24]. It is unanimously agreed in literature that utilization of IK by rural communities in poverty-stricken areas in SSA has helped them to thrive in extremely harsh environments in the past [25, 26]. Historically, IK is said to have contributed significantly to developments in agriculture worldwide, such as domestication of crops and livestock, conservation of agro-biodiversity resources, development of animal traction and exchange of plant and animal species [27]. This implies that IK can be critically important for scaling climate-smart innovations in smallholder agriculture. Policymakers and other stakeholders interested in improving adoption of CSA innovations need to understand that, rural communities have been adapting to climate change even before in various innovative ways and that external interventions can only be successful if they build on what already rural farmers have been doing to adapt to climate. Traditional farmers have developed diverse and locally adapted agricultural systems for centuries, and have managed them with indigenous practices that were often effective in ensuring food security and sustainability [28].

\section{Major Indigenous Practices for Climate Smart Agriculture in SSA}

Indigenous people are good observers of changes in weather and climate and acclimatize through several adaptive and mitigation strategies. CSA includes a number of proven practical techniques which is important in building climate resilience in smallholder farming communities such as Terracing System, Mulching, intercropping, ridge and counter ploughing practice, crop rotation, Mixed farming, Agroforestry, improved grazing, Fallowing, Weather forecasting and water diversion ditch.

\subsection{Crop rotation and Intercropping}

Crop rotation and intercropping practices are cultural practices or system with reduced mechanical tillage based on mulch cover and biological tillage; alternatives have to be developed to control pests and weeds. Practicing crop rotation and intercropping has many advantages, which include reduced risk of pest and weed infestations; better distribution of water and nutrients through the soil profile; exploration for nutrients and water of diverse strata of the soil profile by roots of many different plant species, resulting in a greater use of the available nutrients and water; increased nitrogen fixation through certain plant-soil biota; improved balance of nitrogen, phosphorus and potassium (N-P-K) from both organic and mineral sources and increased formation of organic matter. Better nutrient management through crop rotation can decrease nitrogen fertilizer use by up to $100 \mathrm{~kg} \mathrm{~N}$ per hectare per year, substantially lowering related greenhouse gas (GHG) emissions (nitrous oxide has a global warming potential 310 times greater than $\mathrm{CO}_{2}$ ) as well as reducing the costs of production. Reduced synthetic fertilizer use also leads to reduced greenhouse gas emissions from the manufacturing process and transportation [29].

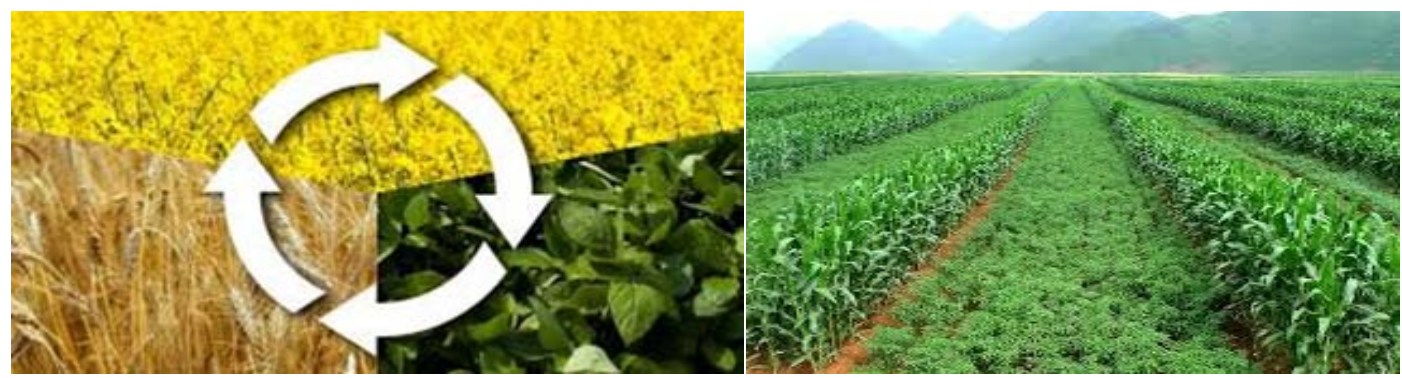

Figure 1. Crop rotation and intercropping practices.

\subsection{Fallowing}

Fallow has been defined as a farming practice wherein no crop is grown and all plant growth is controlled by cultivation or chemicals during a season when a crop might normally be grown. [30]. Fallow as a practice, associated with crop rotation, had its origins in Mediterranean agriculture [31]. Additionally, summer fallow has been practiced widely across the 15 western states of the United States and the farmed areas of the prairie provinces of Canada in response to widely varying precipitation from year to year. For example, precipitation in any given year for a specific site in the central Great Plains region of the United States may range from double to less than half of the long-term average [32].

The primary reason for fallow is to stabilize crop production by forfeiting production in one season in anticipation that there will be at least partial compensation by increased crop production the next season.

\subsection{Weather Forecasting}

In the communities examined, forecasts are linked to the anticipated weather. The people rely on indicators in the sky, on plants or on the behavior of wild and domestic animals. Forecasts can be long term, which corresponds to the months in which rainfall is expected, as well as short term, when forecasts refer to the same day, coming days or seasonal 
changes (with or without rain , storms or notes corresponding to several days of rain).

\subsection{Mixed Farming}

Mixed farming is the one in which crop production is combined with the rearing of livestock. In other word, the practice of growing food crops, cash, feed crops and livestock on the same farm land. The livestock enterprises are complementary to crop production so as to provide a balance and productive system of farming. Its advantage is that it reduces dependence on external sources like fertilizers because the crop and animal components in the farm support each other.

\subsection{Terracing System}

Method of growing crops on sides of hills or mountains by planting on graduated terraces built into the slope. Though labor-intensive, the method has been employed effectively to maximize arable land area in variable terrains and to reduce soil erosion and water loss.

\subsection{Contour Ploughing Practice}

Contour ploughing mitigates the impacts of floods, storms and landslides on the crops by reducing soil erosion up to 50 percent, controlling runoff water, increasing moisture infiltration and retention and thus enhancing soil quality and composition. This practice describes contour ploughing and contour beds which can be constructed manually using on farm equipment. The principles of strip cropping can be integrated into any contour farming practice to promote additional soil conservation benefits.

\subsection{Agroforestry}

The traditional Practice involves the integration of trees and shrubs into farmland either through planting or natural regeneration. Currently, the government of Ethiopia has identified the use of this tree as an important technology for climate change adaptation and promotion is under way in many part of the country. The practices being promoted and tested are intended to address issues of soil fertility, soil erosion and diversification of farm produce as well as agricultural yield, resilience to climate variability (for example through provision of shade during hot spells) and creation of favorable microclimates for certain crops. Integrating perennial trees or shrubs in agricultural lands used both for crop production and grazing [33].

\subsection{Water Diversion Ditch}

Water diversion ditches are a traditional practice which is constructed to reduce soil degradation due to runoff. It constructed along the contour lines and across slopes for the purpose to intercept surface runoff and divert it to suitable outlets. These ditches are the main soil conservation structures to manage runoff in upland areas.

\subsection{Improved Grazing}

Even though, it's not well practiced improved grazing is one of traditional practice or techniques, which indigenous farmers' and pastoralists' are used to feed their livestock and manage their environments.

The environmental benefits of well managed pasture include reduced soil erosion; improved air and water quality; better plant diversity, vigor and production; and improved fish and wildlife habitat. Improving grazing management will result in more complete vegetative cover and improved soil structure that will allow a higher percentage of the rainfall to infiltrate the soil where it can be used for plant growth rather than running off where it can result in soil erosion and sedimentation problems. The overall soil quality improves with improved grazing management.

\subsection{Mulching}

Mulching is the process or practice of covering the soil/ground to make more favorable conditions for plant growth, development and efficient crop production. Mulch technical term means 'covering of soil'. While natural mulches such as leaf, straw, dead leaves and compost have been used for centuries, during the last 60 years the advent of synthetic materials has altered the methods and benefits of mulching. The research as well as field data available on effect of synthetic mulches make a vast volume of useful literature.

\section{Methodology}

Sub-Saharan African countries remained more vulnerable to climate change risks through increased temperature, changes in rainfall patterns and variations in intensity and frequency of extreme weather events such as drought and floods. Review paper used document examination as its main method of data gathering and analysis. Relevant facts on 
the indigenous knowledge for climate smart agriculture in Sub-Saharan Africa. It was undertaken using some review of related literature from different sources. Available articles and books were also explored to organize the document related to indigenous knowledge for climate smart agriculture in Sub-Saharan Africa.

\section{Summary and Conclusion}

Climate alter overall undermines provincial vocations in sub-Saharan Africa (SSA). This can be incompletely since country communities in Africa, especially SSA, are moderately more powerless to the impacts of climate altering than other regions. The SSA locale is uncovered to climate chance through expanded temperature, changes in precipitation designs and varieties in escalated and recurrence of extraordinary climate occasions such as dry season and surges.

Indeed in spite of the fact that changes have been happening over eras, rustic agriculturists have been adjusting to these changes all through their life utilizing neighborhood natural. The information is generally cheap, promptly accessible to rustic ranchers, and it could be a climatically shrewd device for feasible advancement and the administration of climate inconstancy. Natural issues change spatio-temporarily, but rustic ranchers, through proceeded experimentation, trial and mistake, and maintained intelligent with their nearby environment have created a tremendous neighborhood information approximately nature in their region that they utilize in adapting with and fathoming their issues, among which are climate-related issues.

Even though changes have been occurring over generations, rural farmers have been adapting to these changes throughout their life using local environmental. The knowledge is relatively cheap, readily available to rural farmers, and it is a climatically smart tool for sustainable development and the management of climate variability. The below diagram (Figure 2) shows that summary of indigenous practices which traditional farmers' and pastoralist' used to mitigate the effects of climate change according to their local environment.

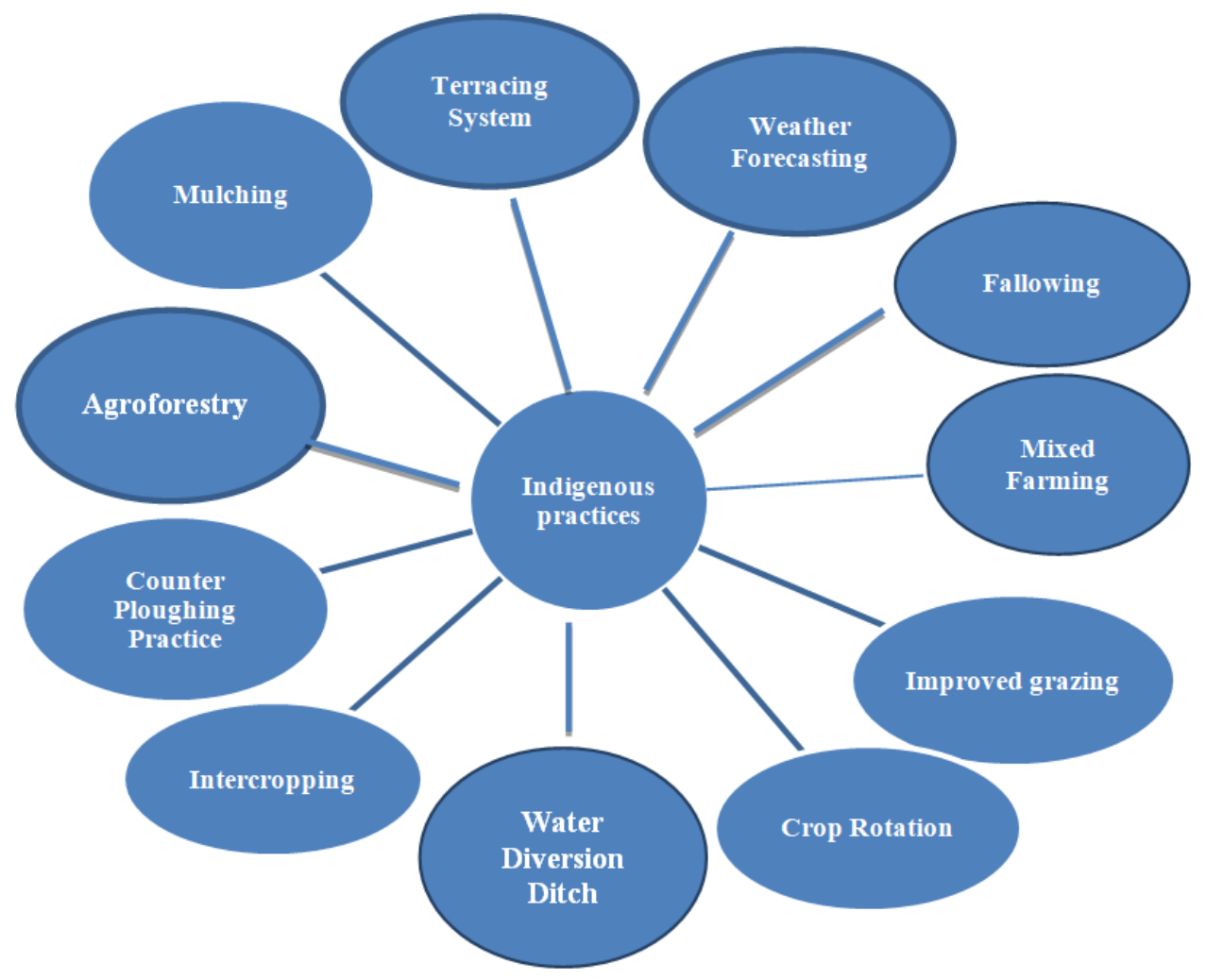

Figure 2. Summary of indigenous practices in climate smart agriculture.

\section{Future Direction}

Based on the conclusions and literature review suggest the following action points for integration of indigenous knowledge for climate smart agriculture in Sub-Saharan Africa. Action points invigorating the part of IK in climate alter impacts administration is likely to progress adjustment to climate alter in smallholder cultivating communities in SSA. Moved forward appropriation and scaling of climate-smart agribusiness developments are likely to advantage essentially in Sub-Saharan Africa which is more vulnerable to climate change impact. 


\section{References}

[1] Belachew Agere, Mekuria Wuletaw, Nachimuthu K. (2020). Factors influencing adoption of soil and water conservation practices in the northwest Ethiopian highlands, Int Soil Water Conserv Res., 8: 80-89. https://doi.org/10.1016/j. iswcr.2020.01.005.

[2] Collier, P. and Dercon, S. (2014). African agriculture in 50 years: smallholders in a rapidly changing world? World development, 63: 92-101.

[3] Kagoya, S., Paudel, K. P., Daniel, N. L. (2017). Awareness and adoption of soil and water conservation technologies in a developing country: a case of Nabajuzi Watershed in Central Uganda. Environ Manage, 61(2): 188-196. https://doi.org/10.1007/s00267-017-0967-4.

[4] IPCC (Intergovernmental Panel on Climate Change). (2014). Climate change: impacts, adaptation, and vulnerability. Part A: global and sectoral aspects, Contribution of Working Group 2 to the Fifth Assessment Report of the IJCCSM 12, 2 284, Cambridge University Press, New York, NY: p. 1132.

[5] Mafongoya, P. and Ajayi, O. C. (2017). Indigenous Knowledge Systems and Climate Change Management in Africa, CTA, Wageningen.

[6] Nchu, I. N., Kimengsi, J. N., and Kapp, G. (2019). Diagnosing climate adaptation constraints in rural subsistence farming systems in Cameroon: gender and institutional perspectives. Sustainability, 11(14): p. 3767.

[7] Boansi, D., Tambo, J. A., and Müller, M. (2017). Analysis of farmers' adaptation to weather extremes in West African Sudan Savanna. Weather and Climate Extremes, 16: 1-13.

[8] Tume, S. J. P., Jumbam, M. S., Nsoseka, N. A., Nyarka, N. D., Yenla, L. J., Njodzeka, N. G. (2018). Role of Media in Climate Change Communication in the Northwest Region of Cameroon. In Handbook of Climate Change Communication: Volume 2 , Climate Change Management; Leal Filho, W., Manola, E., Azul, A., Azeiteiro, U., McGhie, H., Eds, Springer, Cham, Switzerland, pp. 47-60.

[9] Kronik, J., Verner, D., Mearns, R., and Norton, A. (2010). The role of indigenous knowledge in crafting adaptation and mitigation strategies for climate change in Latin America. Social Dimensions of Climate Change. The World Bank, Washington DC: p. 145.

[10] Nyong, A., Adesina, F., and Elasha, B. O. (2007). The value of indigenous knowledge in climate change mitigation and adaptation strategies in the African Sahel. Mitigation and Adaptation Strategies for Global Change, Vol. 12 No. 5: pp. 787-797.

[11] Odero, K. (2011). The role of indigenous knowledge in responding to climate change: local-global perspectives. Panel 10: Roles of local and indigenous knowledge in addressing climate change. In Proceedings of the African Adapt, Climate Change Symposium, Addis Ababa, Ethiopia: pp. 9-11.

[12] Mafongoya, P., Jiri, O., Mubaya, C., and Mafongoya, O. (2017). Using indigenous knowledge for seasonal quality prediction in managing climate risk in Sub-Saharan Africa. Indigenous Knowledge Systems and Climate Change Management in Africa, Centre for Agricultural and Rural Cooperation (CTA), Wageningen: p. 43.

[13] FAO. (2014). FAO success stories on climate-smart agriculture. Rome: Food and Agriculture Organization of the United Nations.

[14] FAO (Food and Agriculture Organization). (2010). The state of food insecurity in the world. Retrieved from www.fao.org/docrep on Tuesday 2nd February, at 8:45 am.

[15] World Bank. (2010). Development and climate change. Retrieved from site resources. worldbank.org/INTWDR2010/.../WDR10 on Monday January 4, 2016 at 07: 59am. Food and Agriculture Organization. (2013). FAO statistical year book 2013. Retrieved from www.fao. Org/docrep on Friday March 11th 2016 at 7:23pm.

[16] FAO (Food and Agriculture Organization). (2018). Climate Smart Agriculture: Building Resilience to Climate Change. Natural Resource Management and Policy, Springer International Publishing AG, Cham, Vol. 52.

[17] Nkonya, E., Jawoo, K., Edward, K., Timothy, J., et al. (2018). Climate risk management through sustainable land and water management in Sub-Saharan Africa. In Lipper, L., McCarthy, N., Zilberman, D., Asfaw, S. and Branca, G. (Eds). Climate Smart Agriculture, Natural Resource Management and Policy, Springer, Cham, Vol. 52, pp. 445-476.

[18] Teklewold Haile Mariam, Menale Kassie, and Bekele Shiferaw. (2013). Adoption of multiple sustainable agricultural practices in rural Ethiopia, Journal of Agricultural Economics, Vol. 64, No. 3: pp. 597-623.

[19] UNFCCC (United Nations Framework Convention on Climate Change). (1992). United Nations Framework Convention on Climate Change (FCC/ INFORMAL/ 84/ Rev.1), Bonn, Germany.

[20] Maslin, M. (2014). Climate Change: A Very Short Introduction. Oxford, UK: Oxford University Press.

[21] Orlove, B., Lazrus, H., Hovelsrud, G. K., and Giannini, A. (2014). Recognitions and responsibilities: On the origins of the uneven attention to climate change around the world. Current Anthropology, 55(3): 249-75.

[22] Mackenzie, R. and Jenkins, M. (2001). Handbook of the convention on biological diversity. Earth scan, London.

[23] Kalanda-Joshua, M., Ngongondo, C., Chipeta, L., and Mpembeka, F. (2011). Integrating indigenous knowledge with conventional science: enhancing localized climate and weather forecasts in Nessa, Mulanje, Malawi, Physics and Chemistry of the Earth, Parts A/B/C. Vol. 36 Nos 14/15: pp. 996-1003. 
[24] Roudier, P., Muller, B., d’Aquino, P., Roncoli, C., Soumaré, M. A., Batté, L., and Sultan, B. (2014). The role of climate forecasts in smallholder agriculture: lessons from participatory research in two communities in Senegal, Climate Risk Management. Vol. 2: pp. 42-55.

[25] Hart, T. and Mouton, J. (2005). Indigenous knowledge and its relevance for agriculture: a case study in Uganda, Indilinga: African Journal of Indigenous Knowledge Systems, Vol. 4, No. 1: pp. 249-263.

[26] Van Veldhuizen, L., Waters-Bayer, A., Ramirez, R., Johnson, D. A. and Thompson, J. (1997). Farmers’ Research in Practice: lessons from the Field, Intermediate Technology Publications, London.

[27] Mettrick, H. (1993). Development-Oriented Research in Agriculture. An ICRA Textbook. The International Centre for Development-Oriented Research in Agriculture (ICRA), Wageningen.

[28] Altieri, M. A. (2004). Linking ecologists and traditional farmers in the search for sustainable agriculture, Frontiers in Ecology and the Environment, Vol. 2, No. 1: 35-42.

[29] PANW. (2012). Crop rotation benefiting farmers, the environment and economy. Friends of the Earth Europe, EU group and APRODEV.

[30] Haas, H. J., W. O. Willis, and J. J. Bond. (ed.) (1974). Summer fallow in the western United States. USDA-ARS Conserv. Res. Rep., No. 17. U.S. Gov. Print. Office, Washington, DC.

[31] Karlen, D. L., G. E. Varvel, D. G. Bullock, and R. H. Cruse. (1994). Crop rotations for the 21st century. Adv. Agron., $53:$ 1-45.

[32] Greb, B. W., D. E. Smika, N. P. Woodruff, and C. J. Whitfield. (1974). Summer fallow in the central Great Plains. Pp. 51-85. In H. J. Haas, W. O. Willis, and J. J. Bond (ed.), summer fallow in the western United States. USDAARS Conserv. Res. Rep., No. 17. U.S. Gov. Print. Office, Washington DC.

[33] Kitalyi, A., Nyadzi, G., Lutkamu, M., Swai, R., and Gama, B. (2011). New climate, new agriculture: how Agroforestry contributes to meeting the challenges of Agricultural development in Tanzania. Tanzanian Journal of Agricultural Sciences, 10(1): 1-7. 